\title{
Intoxicação aguda por Pteridium arachnoideum e Pteridium caudatum em bovinos e distribuição das plantas em Mato Grosso ${ }^{1}$
}

\begin{abstract}
Fernando Henrique Furlan ${ }^{2 *}$, Evelyn R.S. Mendes ${ }^{3}$, Kassia R. Ducatti ${ }^{3}$, Gefferson C. Marcon $^{3}$, Tiago Dombrosky ${ }^{3}$, Tássia M. Amorim ${ }^{3}$ e Franklin Riet-Correa ${ }^{4}$

ABSTRACT.- Furlan F.H., Mendes E.R.S., Ducatti K.R., Marcon G.C., Dombrosky T., Amorim T.M. \& Riet-Correa F. 2014. [Acute poisoning by Pteridium arachnoideum and Pteridium caudatum in cattle and distribution of the plants in Mato Grosso.] Intoxicação aguda por Pteridium arachnoideum e Pteridium caudatum em bovinos e distribuição das plantas em Mato Grosso. Pesquisa Veterinária Brasileira 34(4):343-348. Laboratório de Patologia Animal, Hospital Veterinário, Instituto de Ciências da Saúde, Centro Universitário de Sinop, Universidade Federal de Mato Grosso, Av. Alexandre Ferronato 1200, Distrito Industrial, Sinop, MT 78550-000, Brazil. E-mail: furlan@ufmt.br

Epidemiological features, clinical signs and pathological findings of a spontaneous acute poisoning by Pteridium arachnoideum and Pteridium caudatum in cattle in the State of Mato Grosso, Brazil, are described. The plant distribution, magnitude and some aspects about the pasture invasion by P. arachnoideum and P. caudatum in the State are also described. Pteridium spp. were found in 83 farms from nine counties and 22 of them were submitted to taxonomic identification. P. arachnoideum was found in 22 farms and in two farms also P. caudatum. Deforestation and burning appear to be associated with pasture invasion by Pteridium spp. On the farm where the poisoning occurred 306 cattle were introduced into a pasture of Brachiaria brizantha intensely invaded by $P$. arachnoideum and $P$. caudatum. Twenty two cattle were poisoned by the plants and died. The main clinical signs were hemorrhages, high fever, apathy, fatigue, weakness and recumbency. Gross findings included variable degrees of hemorrhages in several organs and cavities with occasional infarcts. The most consistent histological finding was marked bone marrow aplasia. Epidemiological, clinical and pathological findings associated with the taxonomic identofication of the plant support the diagnosis of acute poisoning by $P$. arachnoideum and P. caudatum in cattle. The increasing rate of deforestation and frequent burning in Mato Grosso can contribute to this disease which becomes a major cause of economic losses to livestock production in the State.
\end{abstract}

INDEX TERMS: Poisonous plants, Pteridium arachnoideum, Pteridium caudatum, bracken fern poisoning, plant distribution, cattle.

RESUMO.- São descritos os aspectos epidemiológicos, clínicos e patológicos de um surto de intoxicação por Pteridium arachnoideum e Pteridium caudatum em bovinos no Esta-

\footnotetext{
${ }^{1}$ Recebido em 7 de março de 2014.

Aceito para publicação em 16 de abril de 2014.

${ }^{2}$ Docente do Laboratório de Patologia Animal, Hospital Veterinário, Instituto de Ciências da Saúde, Centro Universitário de Sinop, Universidade Federal de Mato Grosso (UFMT), Av. Alexandre Ferronato 1200, Distrito Industrial, Sinop, MT 78550-000, Brasil, *Autor para correspondência: furlan@ufmt.br

${ }^{3}$ Graduando em Medicina Veterinária, Instituto de Ciências da Saú-
}

do de Mato Grosso. A distribuição dessas plantas no Estado, a intensidade de invasão de pastagens e alguns fatores associados à invasão das pastagens por Pteridium spp. são

\footnotetext{
de, Centro Universitário de Sinop, UFMT, Av. Alexandre Ferronato 1200, Distrito Industrial, Sinop, MT 78550-000. E-mails: evelyn_rezendevet@ hotmail.com, kassiaducatti@hotmail.com, gefomarcon@gmail.com, tiago_dombroski@hotmail.com, taty.moara@gmail.com

${ }^{4}$ Docente do Laboratório de Patologia Animal, Hospital Veterinário, Centro de Saúde e Tecnologia Rural (CSTR), Universidade Federal de Campina Grande (UFCG), Av. Universitária s/n, Cx. Postal 64, Santa Cecília, Patos, PB 58708-110, Brasil. E-mail: franklin.riet@pq.cnpq.br
} 
também descritos. Pteridium spp. foi observada em 83 propriedades de nove municípios de Mato Grosso e deste total, amostras de 22 propriedades foram coletadas para identificação taxonômica. Em 22 propriedades identifica-se $P$. arachnoideum e em duas dessas havia também $P$. caudatum. 0 desmatamento e a realização de queimadas parecem estar relacionados com a invasão de Pteridium spp. nas pastagens. $\mathrm{Na}$ propriedade em que ocorreu a doença, 306 bovinos foram introduzidos em uma pastagem formada por Brachiaria brizantha intensamente invadida por P. arachnoideum e $P$. caudatum e desses 22 bovinos adoeceram e morreram. Os principais sinais clínicos foram febre alta, apatia, fadiga, fraqueza e decúbito. Na necropsia havia graus variáveis de hemorragias em vários órgãos e cavidades e infartos ocasionais. Microscopicamente, a alteração mais importante consistiu em aplasia severa da medula óssea vermelha. Os achados epidemiológicos, clínicos e patológicos associados à identoificação taxonômica da planta fundamentam o diagnóstico de intoxicação aguda por $P$. arachnoideum e $P$. caudatum em bovinos. 0 crescente desmatamento e a frequente utilização de queimadas em Mato Grosso podem contribuir para que esta doença venha a ser uma importante fonte de prejuízos para a pecuária do Estado.

TERMOS DE INDEXAÇÃO: Plantas tóxicas, Pteridium arachnoideum, Pteridium caudatum, intoxicação por samambaia, distribuição de planta, bovinos.

\section{INTRODUÇÃO}

Pteridium spp. (Dennstaedtiaceae) conhecida popularmente por samambaia-do-campo ou samambaia, está presente em todos os continentes e se desenvolve em solos ácidos, bem drenados e com boa pluviosidade. Até recentemente, o gênero Pteridium era constituído de apenas uma espécie (Pteridium aquilinum), e cinco subespécies; estas subespécies foram elevadas a espécies, das quais duas existem no Brasil (Pteridium arachnoideum e Pteridium caudatum). Pteridium arachnoideum (Kaulf.) Maxon é encontrada principalmente em regiões montanhosas desde o sul da Bahia até o Rio Grande do Sul e em algumas áreas do Distrito Federal e Mato Grosso do Sul, enquanto que P. caudatum (L.) Maxon tem sido observada em áreas baixas da Amazônia no Estado do Amazonas, Acre e Rondônia (Thomson 2000, Prado \& Sylvestre 2010, Tokarnia et al. 2012).

A intoxicação por samambaia se manifesta sob três formas distintas. Duas crônicas onde uma é caracterizada por neoplasias no trato digestivo e outra por lesões na bexiga, denominada hematúria enzoótica (Döbereiner et al. 1967, Tokarnia et al. 1969, Souto et al. 2006a,b). Há ainda a forma aguda que é associada à síndrome hemorrágica (Tokarnia et al. 1967, Marçal et al. 2002, Anjos et al. 2008, 2009). A intoxicação por samambaia é de grande importância em muitos estados do país. Pteridium arachnoideum é a principal causa de intoxicação por plantas em bovinos no estado de Santa Catarina (Borelli et al. 2008) e a segunda principal no Rio Grande do Sul (Rissi et al. 2007). Na região amazônica, todavia não há dados publicados sobre a ocorrência das diversas doenças causadas por Pteridium spp., mas há um relatório sobre a ocorrência da hematúria enzoótica no município de Manacapuru, AM, confirmado através da necropsia e exames histopatológicos de dois casos; naquela região a samambaia presente nas pastagens posteriormente foi identificada como Pteridium caudatum (Tokarnia 1988). 0 objetivo deste trabalho é descrever os aspectos epidemiológicos, clínicos e patológicos de um surto de intoxicação aguda por P. arachoideum e P. caudatum em bovinos e caracterizar as regiões em que essas plantas invadem pastagens em Mato Grosso.

\section{MATERIAL E MÉTODOS}

O surto ocorreu no mês de dezembro de 2010 no município de União do Sul, região norte de Mato Grosso, em uma propriedade com 980 bovinos da raça nelore com idade variando entre 0 e 4 anos. Constatou-se a doença 40 dias após um lote de bovinos machos, com 1 a 2 anos de idade ser transferido para um piquete com pouca disponibilidade de forragem formado por Brachiaria brizantha e invadido por Pteridium spp. Após a morte dos primeiros bovinos o lote foi transferido para outro piquete formado por B. brizantha em melhores condições de pastejo, mas também invadido pela planta e a doença continuou a ocorrer. Estabelecido o diagnóstico, os animais foram transferidos para um piquete arrendado formado por $B$. brizantha, livre de Pteridium spp., no qual ainda houve mais sete mortes nos cinco dias subsequentes. Dos 306 bovinos que compunham o lote, 22 adoeceram e morreram. Realizou-se a necropsia de dois bovinos que morreram espontaneamente (Bovinos 1 e 2) e de um bovino em que foi realizada eutanásia por apresentar-se em estágio avançado da doença (Bovino 3). Fragmentos de tecidos dos bovinos necropsiados foram coletadas em formalina a $10 \%$ e processadas rotineiramente para confecção de lâminas histológicas, coradas através da técnica de hematoxilina e eosina e observadas em microscópio óptico.

Para determinar a distribuição de Pteridium spp., o Estado de Mato Grosso foi dividido em regiões sul, meio norte e norte. Nessas regiões foi realizada uma consulta aos médicos veterinários ou visita aos principais municípios e seus entornos como segue: Região Sul, Cuiabá, Cáceres, Rondonópolis, Barra do Garças; Região Meio Norte, Sinop, Sapezal, Comodoro, Porto dos Gaúchos, Santa Carmen, Marcelândia, Cláudia, União do Sul; Região Norte, Nova Bandeirantes, Paranaíta, Matupá, Apiacás, Confresa e Vila Rica. Amostras de Pteridium spp. de 21 das 83 propriedades visitadas e do surto acompanhado foram identificadas e confeccionadas exsicatas que foram enviadas para classificação taxonômica aos cuidados do Prof. Dr. Alexandre Salino, curador do Herbário do Departamento de Botânica da Universidade Federal de Minas Gerais.

\section{RESULTADOS}

O proprietário relatou que alguns animais eram encontrados mortos sem que fossem observados sinais clínicos. Quadro clínico de cansaço e letargia era constatado à movimentação do lote. Esses bovinos apresentavam inicialmente fraqueza, manifestada sob a forma de movimentos cambaleantes e incoordenação motora, febre alta (entre $41^{\circ} \mathrm{e}$ $42^{\circ} \mathrm{C}$ ), mucosas ocular e oral hipocoradas e com petéquias, além de epistaxe e melena. 0 sangue tinha aspecto aquoso e o tempo de coagulação estava aumentado. Posteriormente o quadro clínico evoluiu para taquipnéia, taquicardia, decúbito esternal e decúbito lateral. 0 curso clínico da enfermidade foi, em média, de três dias, porém o Bovino 3 foi eutanasiado no quarto dia após o início dos sinais clínicos. 
As lesões macroscópicas mais frequentes foram petéquias, equimoses e sufusões multifocais no tecido subcutâneo, nas mucosas, nas serosas e nas cavidades. No tecido subcutâneo, as hemorragias concentravam-se na região ventral e lateral do tórax e do abdômen. A conjuntiva apresentava-se hipocorada e com petéquias multifocais. Na mucosa oral havia petéquias na porção interna dos lábios e gengivas. Nas narinas havia epistaxe e, no Bovino 2, ulcerações multifocais. Na mucosa intestinal observaram-se fezes e sangue misturados a restos necróticos e pequena quantidade de fibrina. Nas serosas de vários órgãos, mesentério e pleura, predominavam as equimoses e sufusões multifocais que eram mais intensas no rúmen, retículo e omaso. Adicionalmente, no Bovino 2, havia ulcerações multifocais no abomaso. Nas cavidades abdominal e torácica observou-se aproximadamente 1,5 litros de sangue livre e/ou coagulado. Adicionalmente, nos rins e no fígado do Bovino 3, havia áreas pálidas multifocais circundadas por áreas estreitas de hemorragia que se estendiam também para o parênquima de ambos os órgãos.

Histologicamente, as principais lesões observadas foram hemorragias e aplasia da medula óssea vermelha. As hemorragias seguiam a distribuição e intensidade descritas macroscopicamente. Em órgãos tubulares as hemorragias ocorriam apenas abaixo da serosa ou, às vezes, estendiam-se até a mucosa. Nos órgãos parenquimatosos foram observadas hemorragias abaixo da serosa e algumas vezes estendendo-se até o interior do parênquima. No intestino, observou-se, ainda, enterite fibrinonecrótica e hemorrágica caracterizada por atrofia ou perda das vilosidades intestinais associadas a infiltrado acentuado de linfócitos, plamócitos e neutrófilos e grande quantidade de hemácias e fibrina. As lesões na mucosa intestinal eram mais intensas nas regiões onde havia placas de Peyer. Todos os animais necropsiados apresentavam aplasia acentuada da medula óssea caracterizadas por rarefação de precursores de hemácias, leucócitos e ausência de megacariócitos. As áreas pálidas visualizadas nos rins e no fígado do Bovino 3 correspondiam a necrose de coagulação aguda associadas a agregados bacterianos e alguns trombos sépticos (Fig.1), adicionalmente havia áreas microscópicas de necrose na língua, baço, encéfalo e pulmão.

Pteridium spp. foi encontrada invadindo pastagens em 83 propriedades nos municípios de Sinop, Porto dos Gaúchos, Comodoro, Nova Bandeirantes, Apiacás, União do Sul, Marcelândia, Cláudia e Matupá (Fig.2). A intensidade de invasão de pastagens bem como a distribuição de $P$. arachnoideum e P. caudatum encontram-se no Quadro 1 . Na propriedade em que a doença ocorreu as amostras coletadas nos piquetes foram classificadas como $P$. arachnoideum e P. caudatum.

Em todos os estabelecimentos nos quais se constatou a presença da planta, as áreas invadidas eram utilizadas exclusivamente para a pecuária. Nestes, os proprietários relataram que havia apenas uma pequena quantidade da planta nas pastagens e que a mesma se alastrou pelos piquetes, muitas vezes chegando a se tornar a vegetação predominante, após a realização de queimadas. Outro fator observado em muitas propriedades foi a crescente expansão das

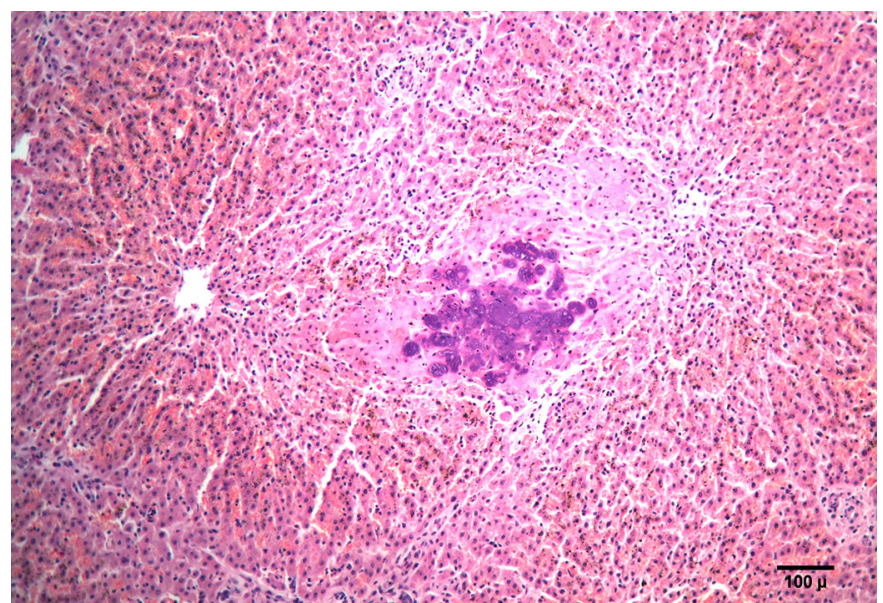

Fig.1. Fígado do Bovino 3 intoxicado por Pteridium arachnoideum e $P$. caudatum. Verifica-se necrose de coagulação aguda associada a agregados bacterianos. HE, Barra $=100 \mu$.

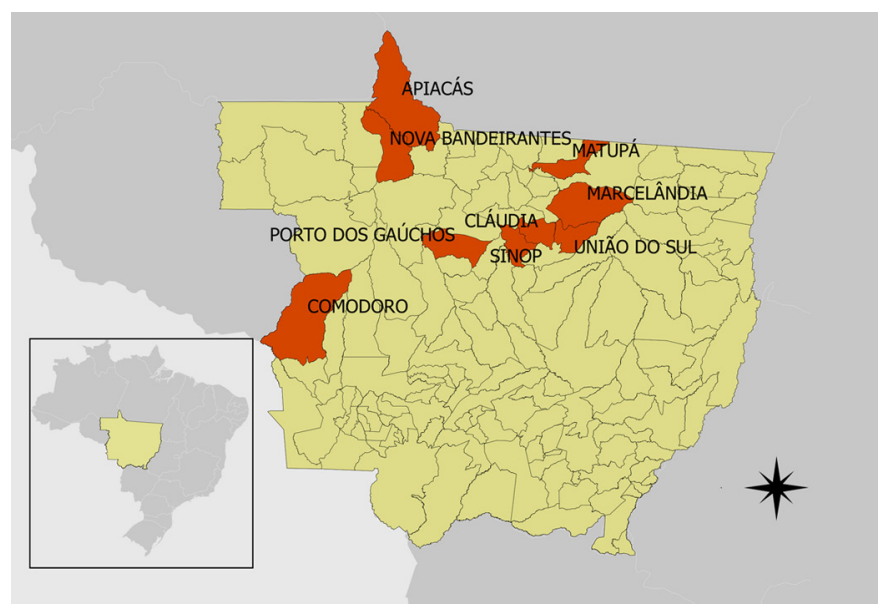

Fig.2. Mapa do Estado de Mato Grosso destacando as cidades onde se verificou a presença de Pteridium arachnoideum e $P$. caudatum.

lavouras de soja, desse modo, áreas antes utilizadas como pastagens deram lugar a agricultura e novas áreas foram desmatadas para alojar o gado. Nessas novas áreas Pteridium spp. tem se alastrado vigorosamente, principalmente após as queimadas. Nessa região, nos estabelecimentos que realizam a cria de gado de corte ou desenvolvem atividade leiteira, com certa frequência, os proprietários relataram que tinham ou já tiveram vacas que periodicamente urinavam sangue. Pteridium spp. não foi observada em áreas utilizadas para agricultura ou áreas em que se que realizava integração lavoura pecuária, mesmo quando estas faziam divisa com piquetes invadidos pela planta. Áreas antes utilizadas como pastagem e que eram severamente invadidas por Pteridium spp., não apresentaram mais invasão pela planta quando passaram a ser utilizadas para o plantio de soja.

\section{DISCUSSÃO E CONCLUSÕES}

O diagnóstico de intoxicação aguda por Pteridium caudatum e $P$. arachnoideum foi fundamentado nos achados epidemiológicos, clínicos, macroscópicos e microscópicos 
Quadro 1. Propriedades com pastagens invadidas por Pteridium spp. distribuídas por municípios e nível de infestação dos piquetes

\begin{tabular}{|c|c|c|c|c|}
\hline Cidade & $\begin{array}{l}\text { № de propriedades amostradas } \\
\text { para classificação taxonônica/ } \\
\text { № de propriedades em que } \\
\text { Pteridium spp. foi observada }\end{array}$ & $\begin{array}{c}P \\
\text { arachnoideum }\end{array}$ & $\begin{array}{c}P \\
\text { caudatum }\end{array}$ & $\begin{array}{l}\text { Nível de infes- } \\
\text { tação das } \\
\text { pastagens }\end{array}$ \\
\hline Sinop & $6 * / 23$ & 6 & 1 & +++ \\
\hline Porto dos Gaúchos & $1 / 6$ & 1 & 0 & + \\
\hline Comodoro & $3 / 10$ & 3 & 0 & ++ \\
\hline Nova Bandeirantes & $1 / 3$ & 1 & 0 & + \\
\hline Apiacás & $1 / 2$ & 1 & 0 & + \\
\hline União do Sul & $5^{*} / 15$ & 5 & 1 & +++ \\
\hline Marcelândia & $2 / 10$ & 2 & 0 & ++ \\
\hline Cláudia & $2 / 8$ & 2 & 0 & ++ \\
\hline Matupá & $1 / 6$ & 1 & 0 & + \\
\hline Total & $22 / 83$ & 22 & $2 *$ & \\
\hline
\end{tabular}

característicos da enfermidade, associados a identificação e classificação taxonômica dessas duas plantas na propriedade em que a doença ocorreu.

No estado de Mato Grosso, Pteridium spp. foi encontrada apenas na região norte do estado, que é composta pelo bioma amazônico. Embora não seja observada em regiões de mata fechada ou em áreas utilizadas para lavoura ou integração lavoura pecuária, ela é abundante em áreas desmatadas utilizadas para a formação de pastagem. Segundo Alonso-Amelot (1999), em regiões fechadas de florestas tropicais a planta não ocorre por encontrar condições incompatíveis com seu desenvolvimento, entretanto seu crescimento é favorecido quando em plena exposição à luz (Marrs \& Watt 2006) como ocorre em áreas recém desmatadas e após a utilização de queimadas. Essas práticas são comuns nessa região de Mato Grosso, onde as áreas mais antigas que eram utilizadas como pastagens dão lugar ao plantio de soja e novas áreas são desmatadas para formação de pastagem. A utilização de queimadas mostrou-se um fator importante para a infestação das pastagens por Pteridium spp. em Mato Grosso, fato observado também por Gava et al. (2002) em Santa Catarina. De modo geral, as regiões invadidas por Pteridium spp. possuem solos pobres e ácidos (Tokarnia et al. 2012). Entretanto, os esporófitos jovens de Pteridium spp. se desenvolvem melhor em pH Alcalino (Gliessman 1978), dessa forma, a elevação significativa no pH do solo que ocorre logo após a queimada (Rheiheimer et al. 2003, Tavares Filho et al. 2011) favorece a germinação de Pteridium spp. (Gliessman 1978). Pouco tempo depois, o solo recupera a acidez que possuía anteriormente à utilização do fogo (Rheiheimer et al. 2003, Tavares Filho et al. 2011), o que favorece o crescimento da planta adulta. Além disso, o fogo elimina as espécies de plantas concorrentes, o que não ocorre com Pteridium spp., uma vez que, mesmo com a destruição de suas partes aéreas pelo fogo, suas formas adultas sobrevivem à queimada pois possuem rizomas profundos que não são atingidos pelo fogo ou, quando possuem rizomas superficiais, os mesmos são resistentes às altas temperaturas (Crane 1990, Roos et al. 2010). Adicionalmente, Pteridium spp. possui efeito alelopático que inibe a germinação de sementes e modifica a morfologia de algumas plântulas, desfavorecendo o crescimento de plantas concorrentes (Silva Santos \& Belinato 2010).

Nas propriedades estudadas, verificou-se que Pteridium spp. não se desenvolveu em áreas utilizadas para lavoura ou integração lavoura pecuária, isso se deve á correção do solo realizada frequentemente nestes sistemas, uma vez que a planta se desenvolve melhor em áreas de solos ácidos (Tokarnia et al. 2012), ou ainda a à outras práticas agrícolas utilizadas nesses sistemas como a lavração, a fertilização e o plantio de outras culturas que lhe tiram a luz.

Nas áreas avaliadas, a espécie de samambaia mais frequentemente encontrada foi Pteridium arachnoideum. Dentre as espécies do gênero Pteridium, $P$. arachnoideum possui a maior distribuição e é a espécie de samambaia mais importante associada a intoxicação de bovinos no Brasil (Prado \& Sylvestre 2010, Tokarnia et al. 2012), embora a intoxicação por $P$. caudatum já tenha sido observada na Amazônia (Tokarnia 1988). A ocorrência de P. caudatum era descrita apenas nos estado do Amazonas, Acre e Rondônia segundo o catálogo de plantas e fungos do Brasil (Prado \& Sylvestre 2010), entretanto, como observado neste estudo, ela ocorre também na região norte de Mato Grosso e pode causar intoxicação em bovinos.

A doença ocorre de forma esporádica ou em pequenos surtos, porém com alta letalidade (Marçal et al. 2002, Anjos et al. 2008). Geralmente os animais ingerem samambaia por fome e em épocas de escassez de alimentos associados a fatores que aumentam a ingestão como grande invasão da planta, carência de fibras e brotação depois de roçadas ou queimadas (Tokarnia et al. 2012). Neste estudo os fatores que levaram ao consumo da planta foram a fome devido a pouca disponibilidade de pastagem e a grande invasão da dos piquetes pela planta.

Clinicamente os animais doentes apresentavam hipertermia acentuada, cansaço, apatia, fraqueza e hemorragias extensas. A febre alta é um sinal clínico importante na fase inicial da doença (Marçal et al. 2002, Anjos et al. 2008,2009 ), porém na fase terminal, alguns animais podem apresentar normotermia (Evans et al. 1954a, Anjos et al. 2009). 0 cansaço, apatia e fraqueza aumentam com a evolução do quadro e ocorrem devido às hemorragias 
(Anjos et al. 2009). 0 curso clínico da doença variou entre 2 e 3 dias após o início dos sinais clínicos. Nos surtos espontâneos de intoxicação por Pteridium arachnoideum têm-se reportado curso clínico semelhante (Marçal et al. 2002, Anjos et al. 2008) entretanto, em intoxicações experimentais, curso clínico de até 6 dias pode ser observado (Anjos et al. 2009). 0 proprietário dos animais deste estudo relata a morte de animais sem que sejam constatados sinais clínicos, tal observação não é descrita na intoxicação por samambaia (Evans et al. 1954a,b,c, Naftalin et al. 1954, Marçal et al. 2002, Anjos et al. 2008, 2009). Provavelmente esses animais consumiram uma grande quantidade da planta e morreram de forma superaguda de modo que os sinais clínicos não pudessem ser observados pelo proprietário no intervalo entre um rodeio e outro nos piquetes que ocorria em média a cada um ou dois dias. Embora não seja frequente, Osebold (1951) observou curso clínico de 4 a 10 horas na intoxicação por samambaia.

A principal lesão microscópica observada nos bovinos estudados consistiu em aplasia acentuada da medula óssea. Esta alteração é frequentemente descrita em casos de intoxicação aguda por Pteridium spp. (Evans et al. 1954a,b,c, Marçal et al. 2002, Anjos et al. 2008, 2009). 0 princípio ativo responsável por esta lesão é um glicosídeo norsesquiterpeno ptaquilosídeo que devido a sua ação radiomimética (Fenwick 1988, Hirono et al. 1984) causa aplasia de medula óssea semelhante à que ocorre em casos de anemia por irradiação (Young 2002). 0 mecanismo envolvido é uma alteração na expressão de genes de células tronco totipotentes e pluripotentes. Tais alterações levam a expressão de moléculas de superfície responsáveis por acionar resposta imune que inibe a proliferação e a diferenciação de células mielóides (Young 2002, Brodsky et al. 2005). A aplasia da medula óssea resulta em trombocitopenia e neutropenia (Marçal et al. 2002, Anjos et al. 2009). A trombocitopenia associada ao aumento da permeabilidade vascular causada pelo consumo da planta (Fenwick 1988, Anjos et al., 2009) teriam levado às hemorragias que culminaram na morte dos animais deste estudo. A neutropenia e a imunossupressão observadas em casos de intoxicação por samambaia (Anjos et al. 2009, Latorre et al. 2009) podem contribuir para a ocorrência de bacteremia (Anjos et al. 2009) o que explica os infartos em vários órgãos observados no Bovino 3.

A intoxicação aguda por samambaia ocorre no estado de Mato Grosso e deve ser considerada, portanto, como um possível diagnóstico para síndromes hemorrágicas em bovinos na região norte deste estado. Embora não tenha sido observado nenhum animal acometido por hematúria enzoótica durante as visitas às propriedades que possuíam pastagens invadidas por Pteridium spp., os frequentes relatos da ocorrência de vacas urinando sangue que pastoreavam nestes piquetes são fortes indícios de que esta doença ocorre em Mato Grosso. A intensidade da invasão de pastagens por $P$. arachnoideum e $P$. caudatum associada ao crescente desmatamento para formação de novos pastos podem fazer com que a intoxicação por Pteridium spp. torne-se uma expressiva causa de prejuízos para a pecuária Mato-Grossense.
Agradecimentos.- À Fundação de Amparo à Pesquisa do Estado de Mato Grosso pelo auxílio financeiro (processo 177848/2012). Ao Prof. Alexandre Salino, curador do Herbário do Departamento de Botânica da Universidade Federal de Minas Gerais pela identificação de P. arachnoideum e $P$. caudatum.

\section{REFERÊNCIAS}

Alonso-Amelot M.E. 1999. Helecho macho, salud animal y salud humana. Revta Fac. Agron., La Plata, Buenos Aires, 16:528-541.

Anjos B.L., Irigoyen L.F., Fighera R.A., Gomes A.D., Kommers G.D. \& Barros C.S.L. 2008. Intoxicação aguda por samambaia (Pteridium aquilinum) em bovinos na região central do Rio Grande do Sul. Pesq. Vet. Bras. 28:501-507.

Anjos B.L., Irigoyen L.F., Piazer J.V., Brum J.S., Fighera R.A. \& Barros C.S.L. 2009. Intoxicação experimental aguda por samambaia (Pteridium aquilinum) em bovinos. Pesq. Vet. Bras. 29:753-766.

Borelli V., Zandonai A., Furlan F.H., Traverso S.D. \& Gava A. 2008. Intoxicação por plantas diagnosticadas em bovinos pelo Laboratório de Patologia Animal CAV/UDESC no período de Janeiro de 2000 a Abril de 2008. Anais Encontro Nacional de Diagnóstico Veterinário, Campo Grande, MS, p.61. (Resumo)

Brodsky R.A. \& Jones R.J. 2005. Aplasic anemia. Lancet 365:1647-1656.

Crane M.F. 1990. Pteridium aquilinum. In: Fire Effects Information System, [Online]. U.S. Department of Agriculture, Forest Service, Rocky Mountain Research Station, Fire Sciences Laboratory (Producer). Disponível em <http://www.fs.fed.us/database/feis/plants/fern/pteaqu/introductory.html> Acessado em jul. 2013.

Döbereinar J., Tokarnia C.H. \& Canella C.F.C. 1967. Ocorrência de hematúria enzoótica e de carcinomas epidermóides no trato digestivo superior em bovinos no Brasil. Pesq. Agropec. Bras. 2:489-504.

Evans W.C., Evans E.T. \& Hughes L.E. 1954a. Studies on bracken fern in cattle. Part I. Brit. Vet. J. 110:295-306.

Evans W.C., Evans E.T. \& Hughes L.E. 1954b. Studies on bracken fern in cattle. Part II. Bracken fern experiments (Lluest farm). Brit. Vet. J.110:365380.

Evans W.C., Evans E.T. \& Hughes L.E. 1954c. Studies on bracken fern in cattle. Part III. Field outbreaks of bovine bracken poisoning. Brit. Vet. J. 110:426-442.

Fenwick G.R. 1988. Bracken (Pteridium aquilinum): toxin effects and toxics constituints. J. Sci. Food Agricult. 46:147:173.

Gliessman S.R. 1978. The establishment of bracken following fire in tropical habitats. Am. Fern J. 68(2):41-44.

Hirono I., Kono Y., Takahashi K., Yamada K., Niwa H., Ojika M., Kigoshi H., Nuyama K. \& Uosaki Y. 1984. Reproduction of acute bracken poisoning in a calf with ptaquiliside, a bracken constituent. Vet. Rec. 115:375-378.

Latorre A.O., Furlan M.S., Sakai M., Fukumasu H., Hueza I.M., Haraguchi M. \& Górniak S.L. 2009. Immunomodulatory effects of Pteridum aquilinum on natural killer cell activity and select aspects of the cellular immune response of mice. J. Immunotoxicol. 6:104-114.

Marçal W.S., Gaste L., Reichert Netto N.C. \& Monteiro F.A. 2002. Intoxicação aguda pela samambaia (Pteridium aquilinum (L.) Kuhn) em bovinos da raça Aberdeen Angus. Arch. Vet. Sci. 7:77-81.

Marrs R.H. \& Watt A.S. 2006. Biological flora of the British Isles: Pteridium aquilinum (L.) Kuhn. J. Ecol. 94:1272-1321.

Naftalin J.M. \& Cushnie G.H. 1954. Pathology of bracken poisoning in cattle. J. Comp. Pathol. Therap. 64:54-74.

Osebold J.W. 1951. An approach to the pathogenesis of fern poisoning in the bovine species. J. Am. Vet. Med. Assoc. 121:276-279.

Prado J. \& Sylvestre L.S. 2010. Samambaias e Licófitas, p.522-569 in: Forzza R.C. (Ed.), Catálogo de Plantas e Fungos do Brasil. Vol.1. Instituto de Pesquisas Jardim Botânico do Rio de Janeiro, Rio de Janeiro. 875p. Disponível em <http://www.jbrj.gov.br/publica/livros_pdf/plantas_fungos_vol1.pdf>

Rheinheimer D.S., Santos J.C.P., Fernandes V.B.B., Mafra A.L. \& Almeida J.A. 
2003. Modificações nos atributos químicos de solo sob campo nativo submetido à queima. Ciência Rural 33(1):49-55.

Rissi D.R., Rech R.R., Pierezan F., Gabriel A.L., Trost M.E., Brum J.S., Kommers G.D. \& Barros C.S.L. 2007. Intoxicações por plantas e micotoxinas associadas a plantas em bovinos no Rio Grande do Sul: 461 casos. Pesq. Vet. Bras. 27:261-268.

Roos K., Rollenbeck R., Peters T., Bendix J. \& Beck E. 2010. Growth of tropical Bracken (Pteridium arachnoideum): response to weather variations and burning. Inv. Plant Sci. Mgmt. J. 3:402-411.

Silva Matos D.M. \& Belinato T.A. 2010. Interference of Pteridium arachnoideum (Kaulf.) Maxon. (Dennstaedtiaceae) on the estabilishment of rainforest trees. Braz. J. Biol. 70(2):311-316.

Souto M.A.A, Kommers G.D., Barros C.S.L., Piazer J.V.M., Rech R.R., RietCorrea F. \& Schild A.L. 2006a. Neoplasias do trato alimentar de bovinos associadas ao consumo espontâneo de samambaia (Pteridium aquilinum). Pesq. Vet. Bras. 26:112-122.

Souto M.A.A, Kommers G.D., Barros C.S.L., Rech R.R. \& Piazer J.V.M. 2006b. Neoplasmas da bexiga associados à hematúria enzoótica bovina. Ciência Rural 36:1647-1650.

Tavares Filho J., Ferreira R.R.M. \& Ferreira V.M. 2011. Fertilidade quími- ca de solo sob pastagens formadas com diferentes espécies nativas e com Brachiaria decumbens manejadas com queimadas anuais. Semina: Ciênc. Agrárias 32(Supl.1):1771-1782.

Thomson J.A. 2000. Morphological and genomicodiversity in the genus Pteridium (Dennstaedtiaceae). Ann. Bot. 85(Suppl.B):77-99.

Tokarnia C.H. 1988. Relatório de viagem ao município de Manacapuru, Estado de Amazonas, para estudar doença em bovinos, no período de 25 a 29 de janeiro de 1988. 3p.

Tokarnia C.H., Döbereiner J. \& Canella C.F.C. 1967. Ocorrência da intoxicação aguda pela "samambaia" (Pteridium aquilinum (L.) Kuhn) em bovinos no Brasil. Pesq. Agropec. Bras. 2:329-336.

Tokarnia C.H., Döbereiner J. \& Canella C.F.C. 1969. Ocorrência de hematúria enzoótica e de carcinomas epidermóides no trato digestivo superior em bovinos no Brasil. Parte I. Estudos complementares. Pesq. Agropec. Bras. 4:209-224.

Tokarnia C.H., Brito M.F., Barbosa J.D., Peixoto P.V. \& Döbereiner J. 2012. Plantas Tóxicas do Brasil para Animais de Produção. $2^{\underline{a}}$ ed. Helianthus, Rio de Janeiro. 566p.

Young N.S. 2002. Acquired aplastic anemia. Ann. Intern. Med. 136:534546. 